\title{
Phenolic Profile and Cholinesterase, Tyrosinase, Urease and Lipid Peroxidation Inhibition Potentials of Artemisia argyi from Ordu, Turkey
}

\author{
Melek Çol Ayvaz* \\ Department of Chemistry, Faculty of Science \& Arts, Ordu University, 52200 Ordu, Turkey. \\ *melekcol@hotmail.com
}

Received: 05 June 2018

Accepted: 18 January 2019

DOI: $10.18466 /$ cbayarfbe. 430835

\begin{abstract}
The present study was designed to reveal a natural resource that could cure for today's major diseases such as Alzheimer, Parkinson and bacterial infection. Furthermore, oxidative stress resulting from lipid peroxidation is a precursor for many diseases. Therefore, anticholinesterase, antityrosinase, antiurease activities and the inhibition potential on lipid peroxidation of methanolic extract of Artemisia argyi collected from Ordu region were tested. The inhibition ratio of extract at $0.3 \mathrm{mg} / \mathrm{mL}$ concentration for asetylcholinesterase and butrylcholinesterase were calculated as 8.45 and $10.68 \%$, respectively. $\mathrm{IC}_{50}$ values for tyrosinase and urease inhibition properties were also found as $0.505 \mathrm{mg} / \mathrm{mL}$ and $0.225 \mathrm{mg} / \mathrm{mL}$. The all obtained values were compared with known corresponding inhibitors such as galantamine, kojic acid and thiourea. Besides these, $0.1 \mathrm{mg} / \mathrm{mL}$ of the extract prevented lipid peroxidation in the ratio of $7.19 \%$. In the scope of this study, the phenolics of the leaves of A. argyi were also analyzed by using HPLC system and pyrogallol was identified as the major component with the $30.16 \mathrm{mg} / \mathrm{kg}$ concentration. On the other hand, benzoic acid was not detected in extract. According to obtained results, A. argyi from Ordu, has the proposed characteristics that it can be a natural resource that can be used in the field of medicine for treatment of various diseases especially Alzheimer and Parkinson, in the cosmetic industry for the elimination of skin problems and in the agricultural field in order to prevent the loss of nitrogenous components.
\end{abstract}

Keywords: Artemisia argyi, Helicobacter pylori, enzyme inhibition, melanogenesis, phenolics,

\section{Introduction}

The Artemisia species, the largest and most widely distributed genus from Anthemideae tribe of the Asteraceae family, have more than 500 taxa. Artemisia species are considered as important medicines throughout the world thanks to their phytochemical content depending on chemical and biological properties. Antitumor, anticancer, antidiabetic, antiinflammatory, antimutagenic, antimalarial, antihypertensive, anti-histaminic, antibacterial, antioxidant, antiviral and anticoagulant/antiplatelet effects of Artemisia species can be considered as health benefits [1]. However, these features vary between different Artemisia species. In addition, environmental factors play a significant role in growth as well as the content of active compounds responsible for these activities. Artemisia argyi, one of the most well-known species, is a herbaceous perennial plant of Compositae artemisia distributing throughout China and used widely as a traditional Chinese medicine [2].

Because of abnormal functioning of enzymes causes communicable and metabolic human diseases, enzymes are regarded as drug targets. In this way, these kind of diseases can be treated by regulating enzyme activity.
One of the abnormal conditions is that the overexpression of the enzyme. In similar cases, restricting the enzyme activity by enzyme inhibitors which are molecules that have pharmacological effects thanks to their inhibition character on particular enzymes is the best approach for treatment. A great source of bioactive molecules with medicinal value to treat many diseases thanks to their inhibition potentials on several enzymes are hidden in nature. So studying and development of enzyme inhibitors is one way to find new drugs.

Alzheimer disease (AD) is a major health problem due to its severe, chronic and progressive neurodegenerative character. Especially in developed countries, it is the majority of deaths among the elder population. Despite being known for more than hundred years, treatment strategies of $\mathrm{AD}$ are still limited. Among the various treatment methods, the most preferred one is the inhibition of hydrolysis of cholinergic neurotransmitters, acetylcholine and butrylcholine, by cholinesterase inhibitors [3].

Tyrosinase has an important role in initial step of melanin biosynthesis. Although, melanin plays an important role in protecting the skin, overproduction of 
it can lead to a variety of dermatological disorders including skin cancer. Moreover, recent investigations exhibited the link between many melanogenesis disorders and neurodegenerative diseases, including Parkinson's, Alzheimer's and Huntington's diseases. Because tyrosinase may play a role in the human brain for neuromelanin formation. Therefore, to prevent the development of said diseases, inhibition of melanogenesis is one of the most important requirements. So, the clinical need continues for melanogenesis-inhibiting agents. Using of drugs targeting tyrosinase for treating melanogenesis is a classical approach, but many of these have various unwanted side effects [4-6].

Urease which is a key enzyme for nitrogen cycle catalyses the hydrolysis of urea in to $\mathrm{CO}_{2}$ and $\mathrm{NH}_{3}$. Urease has a role in the colonization of Helicobacter pylori in gastric epithelium by adjusting the stomach $\mathrm{pH}$. However, the bacterial infection causes many diseases such as inflammation, pyelonephritis, ulcers and adenocarcinoma. Such diseases can be treated with antibiotic use. However, the increasing resistance of bacteria towards antibiotics requires new approaches in this area. Therefore, inhibition of urease activity is effective on the treatment of $H$. pylori related diseases. Because of the urea is used as a nitrogen fertilizer in agriculture worldwide, another benefit of urease inhibitors is agronomic and environmental by preventing excessive ammonia loss to the atmosphere by adding to urea or urea-containing fertilizers $[7,8]$.

Synthetically produced inhibitors for these three enzyme have been used. Despite they were successful, they have several side effects. Because of these reasons the search for drugs without side effects from natural sources on the rise. For example memory improvement effect of A. argyi $\mathrm{H}$. fermented with Monascus purpureus on streptozotocin-induced diabetic mice [9] and antimelanogenic activities of essential oils from $A$. argyi leaves [2] had been investigated. In addition to these, report about urease inhibitory activity of aerial parts of Artemisia scoparia [8], is another study contributing to this field.

Besides enzymatic inhibition strategies to prevent the development of diseases, it is necessary to overcome the problems like lipid peroxidation which develops after oxidative stress. Lipids are known as main components of the cell membrane and autoxidation of them is called as lipid peroxidation. The first step of lipid peroxidation which have a series of reactions is breaking of an electron from unsaturated fatty acids by reactive oxygen species. By this way, lipid peroxidation results with the formation of saturated fatty acids and the membrane permeability and thus the life time of the cells are reduced. Because of the brain contains high levels of poly-unsaturated fatty acids, central nervous system is one of the major targets of lipid peroxidation [10] and it can be regarded as the main problem of many neurodegenerative diseases.
According to report of Melguizo-Melguizo et al., [11] despite the essential oil of this plant has been widely studied, the polar fraction which contains mainly phenolic compounds responsible for their biological activity and health benefits has been less searched. In this context, the phenolic component of which we thought might be responsible for said inhibitory potencies of the plant was also investigated.

When the literature is carefully examined, it is noteworthy that most studies on enzyme inhibition potentials of Artemisia species concentrate on species other than A. argyi. Furthermore, the lack of the studies on Artemisa species from Turkey, led us to this research. This study ensures an overview on the inhibition potentials of $A$. argyi on many crucial enzyme activities and lipid peroxidation. Besides these, phenolic profile of the obtained sample was scanned to get information about the phenolics of the methanolic extract. Thus, it was aimed that to contribute to the fields of pharmacology, medicine, cosmetics and agriculture in the direction of the results obtained.

\section{Materials and Methods}

\subsection{Chemicals and instruments}

All chemicals used were of analytical grade and purchased from Sigma Chemical Co. (St. Louis, MO, USA). Acetylcholinesterase and Butyrlcholinesterase were from Electrophorus electricus (electric eel) and equine serum, respectively. Tyrosinase and urease were also from mushroom and Canavalia ensiformis (Jack bean), respectively. Spectrophotometric measurements were performed by using an UV-1800.

\subsection{Plant material and sample preparation}

A. argyi samples were collected from Ordu Province of Turkey. The harvested aerial parts were subjected to freeze-drying using a lyophilizator and grinded to a fine powder. To obtain methanolic extract, $60 \mathrm{~g}$ of powdered samples were added to $250 \mathrm{~mL}$ of methanol and extracted at room temperature for $48 \mathrm{~h}$. At the end of this, the mixture was centrifuged and the supernatant was removed. The extraction solvent was removed under vacuum using a rotary evaporator at $25^{\circ} \mathrm{C}$ after all the supernatants were combined. Weighed dry parts were dissolved by the addition of methanol. Thus, a stock solution was obtained. All tests were carried out using the diluted amounts of this solution in the appropriate volumes.

\subsection{Detection of inhibitory activity against enzymes}

$\mathrm{AChE}$ and BuChE inhibitory activities were measured by following the method developed by Ellman et al [12] Electric eel $\mathrm{AChE}$ and BuChE from equine serum were used as enzyme, while acetylthiocholine iodide and butyrylthiocholine chloride were used as substrates. The reaction mixture was firstly prepared to contain 0.2 M 5,5'-Dithio-bis(2-nitrobenzoic) acid (DTNB) and $0.2 \mathrm{M}$ enzyme solution and incubated for $15 \mathrm{~min}$ at 
$25^{\circ} \mathrm{C}$. The reaction was then initiated with the addition of $0.2 \mathrm{M}$ of each substrate. Hydrolysis of substrates was monitored by the formation of the yellow 5-thio-2nitrobenzoate anion as a result of the reaction of DTNB with thiocholines, catalyzed by enzymes at $412 \mathrm{~nm}$ $\left(\mathrm{Abs}_{\text {sample }}\right)$

AChE/BuChE inhibition percentage was determined by comparison reaction rates of samples relative to blank sample (methanol as extraction solvent in phosphate buffer, $\mathrm{pH} 8$ ) using the following equation.

Inhibition ratio $(\%)=\left(\mathrm{Abs}_{\text {blank }}-\mathrm{Abs}_{\text {sample }}\right) / \mathrm{Abs}_{\text {blank }} \mathrm{x} 100$

Galantamine, alkaloid-type anticholinesterase, was used as reference.

To evaluate anti-tyrosinase activity of methanolic extract of $A$. argyi leaves, mushroom tyrosinase $(0.5 \mathrm{mg} / \mathrm{mL})$ was firstly incubated with extract in phosphate buffer $(50 \mathrm{mM}, \mathrm{pH} 6.8)$ for $10 \mathrm{~min}$ at room temperature. Following incubation $0.5 \mathrm{mM}$ of L-DOPA as substrate was added to this mixture and change in absorbance at $475 \mathrm{~nm}$ as an indication of the enzymatic reaction due to formation of DOPA chrome was monitored. The percent of inhibition of tyrosinase reaction was calculated by using equation used for AChE/BuChE inhibition activity. Kojic acid was used as reference standard inhibitor for comparison.

In order to demonstrate whether $A$. argyi extract is effective on urease inhibition, $10 \mu \mathrm{L}$ of urease enzyme solution containing $1 \ddot{U}(0.02 \mathrm{mg})$ jack bean urease was mixed with phosphate buffer $(50 \mathrm{mM}, \mathrm{pH}$ 6.8) containing $100 \mathrm{mM}$ urea and different amounts of extract. The mixtures were incubated for $15 \mathrm{~min}$ at $30^{\circ} \mathrm{C}$. Urease activity was determined by measuring ammonia formation using indophenol method [13]. For this purpose, $50 \mu \mathrm{L}$ of phenolic reagent $(1 \%(\mathrm{w} / \mathrm{v})$ phenol and $0.005 \%(\mathrm{w} / \mathrm{v})$ sodium nitroprusside) and $50 \mu \mathrm{L}$ of alkali reagent $(0.5 \% \quad(\mathrm{w} / \mathrm{v}) \mathrm{NaOH}$ and $0.1 \%(\mathrm{v} / \mathrm{v}) \mathrm{NaOCl})$ were added to each tube. After $50 \mathrm{~min}$, the absorbance was measured at $630 \mathrm{~nm}$. The percent of urease reaction inhibition was calculated for each extract concentration and $\mathrm{IC}_{50}$ value the concentration of sample causing 50\% inhibition of maximal activity was calculated from the graph between concentration and inhibition ratio.

\subsection{Detection of lipid peroxidation inhibition}

Inhibition potential of the methanolic extract on 2,2'azobis-(2-amidinopropane)-dihydrochloride (ABAP)induced lipid peroxidation was also investigated. The reaction mixture including $0.26 \mathrm{mM}$ of linoleic acid solution, $0.1 \mathrm{mg} / \mathrm{mL}$ of $A$. argyi extract and $2 \mathrm{mM}$ of ABAP was prepared. After mixing, changes happening in absorbance at $234 \mathrm{~nm}$ with time were measured as spectrophotometrically and lipid peroxidation inhibition potential was expressed as a percentage by taking advantage of the difference between the absorbance values at the beginning and at the end of the period.

\subsection{HPLC analysis}

Eighteen standards of phenolic compounds (Gallic acid, Protocatechuic acid, p-OH benzoic acid, vanillic acid, benzoic acid, catechin, p-coumaric acid, trans-cinnamic acid, caffeic acid, ferulic acid, trans cinnapic acid, homogentisic acid, chlorogenic acid, gentisic acid, quercetin, myricetin, resveratrol and pyrogallol) were analyzed using HPLC system (Thermo Dionex Ultimate 3000) with a RS Diode Array detector. Analyzes were carried out by using ODS HYPERSIL C18 column (150 $\mathrm{mm} \times 4.6 \mathrm{~mm})$. Phenolic compounds in the prepared extract were analyzed using gradient elution (solution $\mathrm{A}, 0.1 \%$ acetic acid, and solution $\mathrm{B}$, acetonitrile): $0 \mathrm{~min}$, $100 \%$ A; 2 min, 5\% B; 20 min, 40\% B; 30 min, 80\% B. Optimization of operation provided by adjusting the injection volume of samples and standards to $10 \mu \mathrm{L}$, flow rate to $0.9 \mathrm{~mL} / \mathrm{min}$, temperature of column to $25^{\circ} \mathrm{C}$

Detected phenolic compounds in methanolic extract of A. argyi were identified through comparison of their retention times and obtained spectra by injection of the standard solution under the same conditions. Peak area was used for quantitation, using external calibration with standards. All standard calibration curves showed almost high degrees of linearity.

\section{Results and Discussion}

Secondary metabolites from crude extracts of several plants have been shown to be neuroprotective. They have ability to enrich the activities of the central nervous system and contribute to human brain functions. Alzheimer's disease is the first one that comes to mind when referring to central nervous system disorders. Investigations on compounds isolated from herbs and extracts or fractions prepared by using plants have shown that they contain signaling molecules that have features that can protect against Alzheimer. The beneficial effects of these herbaceous substances on Alzheimer are associated with their antioxidative, antiapoptotic and anti-inflammatory activities. Because there are proofs that oxidative stress plays a role in development of Alzheimer's [3].

These known facts have led us to investigate whether the methanol extract prepared from A. argyi leaves, which has been demonstrated to have good enzymatic and nonenzymatic antioxidant activity by another study of our group, has an effect on Alzheimer's. It is the most preferred method to study the effect of extract on cholinesterases at this point. Because inhibition of the acetylcholinesterase is considered as one of the prime therapeutic strategies providing symptomatic and moderate disease-modifying effects on Alzheimer.

The methanolic extract was tested for cholinesterase inhibition potentials and the calculated results were compared with standart inhibitor galantamine. According to this licensed drug, the extract showed very low activity. But side effects of it including 
gastrointestinal anomalies and hepatotoxicity are known and new resources that are thought to have no side effects become precious. Acetyl- and butrylcholinesterase inhibition ratios for $0.3 \mathrm{mg} / \mathrm{mL}$ of A. argyi extract was calculated as 8.45 and $10.68 \%$, respectively. But for $7.7 \mu \mathrm{g} / \mathrm{mL}$ of galantamine, the inhibition ratios were $89.324 \%$ and $7.323 \%$ for $\mathrm{AChE}$ and BuChE, respectively (Table 1). Dey et al. [3] had reported that Artemisia asiatica Nakai ex Pamp. (Asteraceae) was proved by Heo et al. [14] as another species of Artemisia to have AChE inhibitory activity. Furthermore, it has also been proven that ethanol extract of this same strain exhibits anti-photoaging activity by suppressing tyrosinase activity through different pathways [15] and Artemisia verlotiorum had also antimelanogenic activity due to its anti-tyrosinase activity $\left(\mathrm{IC}_{50}=79.69 \mu \mathrm{g} / \mathrm{mL}\right)[6]$. On the other hand, thanks to similar activities Artemisia abrotanum L. is used as an anti-wrinkle agent in cosmeceutical formulations [5]. Artemisia umbelliformis is known as White genepi is also used in cosmeceutical formulations with its antioxidant property [16]. As it can be understood there are numerous works on this subject, but those made on tyrosinase inhibition potential of $A$. argyi are rare. Consequently, the tyrosinase inhibition effect of prepared methanolic extract of A. argyi sample and kojic acid (a well-known inhibitor for mushroom tyrosinase) were tested and $\mathrm{IC}_{50}$ values were calculated as $0.505 \mathrm{mg} / \mathrm{mL}$ and $0.027 \mathrm{mg} / \mathrm{mL}$, respectively. In the study by Huang et al. [4], different concentrations of essential oils extracted from $A$. argyi leaves had exhibited anti-tyrosinase activities at different degrees but definitely less than kojic acid. It can be said that when compared to these results, A. argyi sample from Ordu has a potency of inhibition of tyrosinase at an acceptable level.

In the same way, $0.225 \mathrm{mg} / \mathrm{mL}$ of the studied sample has the potential to inhibit urease activity by $50 \%$. The

Table 1. Inhibition potential of $A$. argyi extract on lipid peroxidation and enzyme activities.

\begin{tabular}{|c|c|c|}
\hline $\begin{array}{c}\text { Type of } \\
\text { inhibition }\end{array}$ & $\begin{array}{c}\text { Extract } \\
\text { concentration } \\
(\mathbf{m g} / \mathbf{m L})\end{array}$ & $\begin{array}{c}\text { Inhibition } \\
\text { rate }(\boldsymbol{\%})\end{array}$ \\
\hline $\begin{array}{c}\text { Lipid } \\
\text { peroxidation }\end{array}$ & 0.1 & 7.189 \\
\hline AChE & 0.3 & 8.45 \\
\hline BuChE & 0.3 & 10.68 \\
\hline Tyrosinase & 0.505 & 50 \\
\hline Urease & 0.225 & 50 \\
\hline
\end{tabular}

$\mathrm{IC}_{50}$ value obtained is quite high when compared to the value found for the standard inhibitor thiourea ( $\mathrm{IC}_{50}=3.07 \mu \mathrm{g} / \mathrm{mL}$ ), but it is noteworthy compared to those found for other Artemisia species in the literature.

Artemisia scoparia had been reported as another Artemisia species determined to have urease inhibitory activity [8]. The $\mathrm{IC}_{50}$ value calculated for it as $4.1 \mathrm{mg} / \mathrm{mL}$ was much higher than that obtained in the present study and it can be said that the urease inhibition potential of $A$. argyi is higher. Because of some urease induced diseases and pathogen infections in human and animal cells, this degree of urease inhibition is very valuable thanks to a natural source. Urease inhibition is not only important for health but also for agricultural food production. When urea is used as a fertilizer in agricultural areas, urease may cause the loss of nitrogenous nutrients [7].

One of the inhibition parameters examined in the context of this study was lipid peroxidation. Because there are studies showing that pharmacologically investigated Artemisia campestris L. [17] and Artemisia apiacea [18] have the activity of inhibiting lipid peroxidation. Lipid peroxidation is one of the major sources of free radical- mediated injury that directly damages neuronal membranes and yields a number of secondary products such as 4-hydroxy-2-nonenal and malondialdehyde, responsible for extensive cellular damage [10]. According to the results of performed test, $0.1 \mathrm{mg} / \mathrm{mL}$ of the extract inhibited ABAP induced lipid peroxidation by $7.19 \%$.

If Table 1 is carefully examined, it can easily be seen that the effects of the crude extract on lipid peroxidation and, in particular, inhibition effects on tyrosinase and urease enzymes are much higher compared to the inhibition effects on cholinesterases.

Both all obtained results and findings in the literature indicate that observed benefits of the extract have been attributed to the presence of several flavonoids and phenolic compounds in it [19]. To explore the phenolic profile of the A. argyi extract, it was analyzed by HPLC and results are summarized in Table 2.

Table 2. The amount of phenolic acids in methanol extract from $A$. argyi.

\begin{tabular}{|c|c|}
\hline Phenolics & Amount $\mathbf{( m g / k g )}$ \\
\hline Pyrogallol & 30.165 \\
\hline p-OH benzoic acid & 7.757 \\
\hline Catechin & 21.464 \\
\hline Vanillic acid & 2.475 \\
\hline Caffeic acid & 3.877 \\
\hline Trans-cinnapic acid & 10.345 \\
\hline Protocatechuic acid & 1.729 \\
\hline Resveratrol & 5.457 \\
\hline Trans-cinnamic acid & 1.926 \\
\hline Gallic acid & 0.908 \\
\hline Homogentisic acid & 19.309 \\
\hline p-Coumaric acid & 3.609 \\
\hline TOTAL & 109.020 \\
\hline
\end{tabular}

Twelve phenolic compounds were identified and quantified (Fig 1). Pyrogallol was determined as main component while the minor compound among the scanned compounds was gallic acid. Similarly, phenolic compounds of Artemisia arborescens had been investigated and presence of 7 phenolic acids and 5 flavonoids was reported by Dhibi et al [19]. 


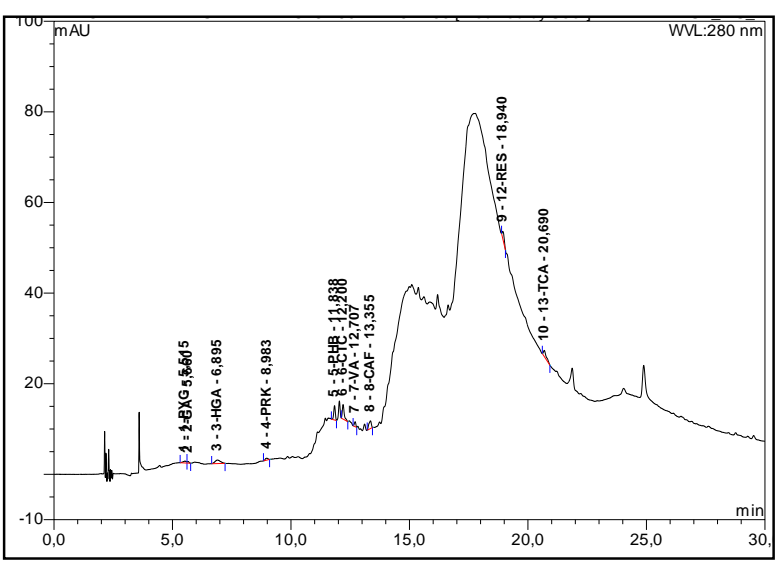

Figure 1. HPLC Chromatogram of sample at $280 \mathrm{~nm}$.

As we have already mentioned, there are not many findings in the literature about phenolic compounds of Artemisia species. The most detailed evaluation was done on Artemisia herba-alba [20]. So, the findings are important.

\section{Conclusion}

In this study, the results of works carried out on enzyme and lipid peroxidation inhibitory potentials of $A$. argyi from Ordu were reported. Obtained findings are valuable, because there is no similar works on Artemisia species collected from Turkey, particularly Black Sea Region. Although other Artemisia species have been studied in terms of these enzyme inhibition potentials, there is no report on Artemisia argyi yet. Furthermore phenolic profile of the studied sample was investigated and the synergistic effect of all the phenolic and nonphenolic ingredients in the crude extract has contributed to these therapeutic properties. With these revealed potentials, A. argyi plant collected from Ordu province can take place especially in the treatment of skin problems and stomach disorders. Furthermore, it may be involved in the preparation of various preparations which may be used in the treatment of diseases such as Alzheimer's and Parkinson's provided that it is further tested.

\section{Acknowledgement}

I would like to gratefully thank Onur Kolören and Zeynep Kolören due to supply of study material A. argyi and good intentions.

\section{Ethics}

There are no ethical issues after the publication of this manuscript.

\section{References}

1. Lee, JH, Lee, JM, Lee, SH, Kim, YG, Lee, S, Kim, SM, Cha, SW 2015. Comparison of Artemisinin Content and Antioxidant Activity from Various Organs of Artemisia Species. Horticulture, Environment, and Biotechnology; 56(5): 697-703.

2. Huang, HC, Wang, HF, Yih, KH, Chang, LZ, Chang, TM. 2012. Dual Bioactivities of Essential Oil Extracted from the Leaves of Artemisia argyi as an Antimelanogenic versus Antioxidant Agent and Chemical Composition Analysis by GC/MS. International Journal of Molecular Sciences; 13(11): 14679-14697.
3. Dey, A, Bhattacharya, R, Mukherjee, A, Pandey, DK. 2017. Natural products against Alzheimer's disease: Pharmaco-therapeutics and biotechnological interventions. Biotechnology Advances; 35(2):178216.

4. Zhang, LB, Lv, JL, Chen, HL, Yan, XQ, Duan, JA. 2013. Chemical constituents from Artemisia argyi and their chemotaxonomic significance. Biochemical Systematics and Ecology; 50: 455-458.

5. Anthonavage, MMS, Saliou, C, Tucker-Samaras, S, Zedayko, T. 2011. Clinical benefits of topical application of Artemisia abrotanum L. (southernwood) on photodamaged skin. Journal of the American Academy of Dermatology; 64(2, Suppl. 1): AB22

6. Chiari, ME, Joray, MB, Ruiz, G, Palacios, SM, Carpinella, MC. 2010 Tyrosinase inhibitory activity of native plants from central Argentina: Isolation of an active principle from Lithrea molleoides. Food Chemistry; 120(1): 10-14.

7. Modolo, LV, de Souza, AX, Horta, LP, Araujo, DP, de Fátima, A. 2015. An overview on the potential of natural products as ureases inhibitors: A review. Journal of Advanced Research: 6(1), 35-44.

8. Khan, MA, Khan, H, Tariq, SA, Pervez S. 2014. Urease inhibitory activity of aerial parts of Artemisia scoparia: exploration in an in vitro study. Ulcers; Article ID 184736, 5 pages.

9. Lee, CJ, Lee, DS, Kang, JY, Kim, JM, Park, SK, Kang, JE, Kwon, BS, Park, SH, Park, SB, Ha, GJ, Heo, HJ. 2017. Memory improvement effect of Artemisia argyi H. fermented with Monascus purpureus on streptozotocin-induced diabetic mice. Korean Journal of Food Science and Technology; 49(5):550-558.

10. Sultana, R, Perluigi, M, Allan, Butterfield, D. 2013. Lipid peroxidation triggers neurodegeneration: A redox proteomics view into the Alzheimer disease brain. Free Radical Biology and Medicine; 62: $157-169$.

11. Melguizo-Melguizo, D, Diaz-de-Cerio, E, Quirantes-Piné, R, ŠvarcGajic', J, Segura-Carretero, A. 2014. The potential of Artemisia vulgaris leaves as a source of antioxidant phenolic compounds. Journal of Functional Foods; 10: 192-200.

12. Ellman, GL, Courtney, KD, Andres, V, Featherstone, RM. 1961. A new and rapid colorimetric determination of acetylcholinesterase activity. Biochemical Pharmacology; 7(2):88-95.

13. Weatherburn, MW. 1967. Phenol-hypochlorite reaction for determination of ammonia. Analytical Chemistry; 39(8): 971-974.

14. Heo, HJ, Yang, HC, Cho, HY, Hong, B, Lim, ST, Park, HJ, Kim, KH, Kim, HK, Shin, DH. 2000. Inhibitory effect of Artemisia asiatica alkaloids on acetylcholinesterase activity from rat PC12 cells. Molecules and Cells; 10(3):253-262.

15. Jeong, D, Lee, J, Jeong, SG, Hong, YH, Yoo, S, Han, SY, Kim, JH, Kim, S, Kim, JS, Chung, YS, Kim, JH, Yie, YS, Cho, JY. 2018. Artemisia asiatica ethanol extract exhibits anti-photoaging activity. Journal of Ethnopharmacology; 220: 57-66.

16. Appendino, G, Scafati, OT, Romano, A, Pollastro, F, Avonoto, C, Rubiolo, P. 2009. Genepolide, a sesquiterpene gamma lactone with a novel carbon skeleton from mountain wormwood (Artemisia umbelliformis L.). Journal of Natural Products; 72(3): 340-344.

17. Dib, I, Angenot, L, Mihamou, A, Ziyyat, A, Tits, M. 2017. Artemisia campestris L.: Ethnomedicinal, phytochemical and pharmacological review. Journal of Herbal Medicine; 7: 1-10.

18. Kim, KS, Lee, S, Lee YS, Jung, SH, Park, Y, Shin, KH, Kim, BK. 2003. Anti-oxidant activities of the extracts from the herbs of Artemisia apiacea. Journal of Ethnopharmacology; 85: 69-72.

19. Dhibi, S, Bouzenna, H, Samout, N, Tlili, Z, Elfeki, A, Hfaiedh, N. 2016. Nephroprotective and antioxidant properties of Artemisia arborescens hydroalcoholic extract against oestroprogestative-induced kidney damages in rats. Biomedicine \& Pharmacotherapy; 82: 520527.

20. Bourgou, S, Rebey, I B, Mkadmini, K, Isoda, H, Ksouri, R, Ksouri, WM. 2017. LC-ESI-TOF-MS and GC-MS profiling of Artemisia herba-alba and evaluation of its bioactive properties. Food Research International; 99(Pt1): 702-712. 